\title{
La capilla de la Santa Vera Cruz (costumbres menestrales en Lima virreinal)
}

\author{
Martha Barriga Tello \\ Departamento de Arte
}

\begin{abstract}
T a pequeña iglesia de la Veracruz responde a algunas singularidades que la convierten en un caso interesante para la historia del arte en Lima. La historia de su construcción y de la función a la que finalmente fue destinada, evidencian aspectos que deben considerarse acerca de la dinámica que acompañaba estos procesos, así como de los hechos alrededor del contexto, el sector social para el cual se produjeron y las implicancias que como monumentos tuvieron para la población. El edificio, por ejemplo, alberga una cofradía que este año cumplirá 462 años de existencia, una de las más antiguas instaladas en la ciudad.
\end{abstract}

La cofradía es una asociación de individuos que se organizan por razones de carácter piadoso asistencial, bajo una advocación específica, que responde a causas diversas y se rige por estatutos. La cofradía de la Vera Cruz la fundó Francisco Pizarro y sus compañeros en 1541, aunque posteriormente recibió a otros aspirantes. Algunos de los cofrades fueron Hernando Pizarro, Domingo de Santo Tomás, Tomás de San Martín, Gaspar de Carvajal y otros conspicuos miembros de la incipiente sociedad virreinal, civiles y religiosos. ${ }^{1} \mathrm{Al}$ principio, su sede estuvo establecida en una capilla en la zona del presbiterio, al lado de la Epístola, en la iglesia dominica de Nuestra Señora del Rosario, que por entonces se estaba edificando. El rey Carlos V, entre otros privilegios que le concedió, tuvo la deferencia de solicitar al papa Paulo III una reliquia mayor para esta cofradía, confiando que así contribuiría a la paz entre las facciones pizarrista y almagrista, enfrascados en una enconada oposición por el dominio del territorio Inca y cuyo resultado fue el asesinato de ambos caudillos. Atendiendo el pedido del rey, el Papa envió un fragmento del Sanctum Lignum Crucis, con el dominico Juan Bautista Roca, que la depositó en la sede de su Orden. Las

Álvarez Vita, Juan. «450 años de historia. Archicofradía de la Vera Cruz». El Comercio, suplemento dominical, Lima, 29 de diciembre, 1991: 6. 
fuentes señalan que éste fue el trozo de mayor dimensión destinado a sede alguna en la cristiandad. ${ }^{2}$

El local institucional fue establecido entre los dominicos. Cuando se construyó el templo de Nuestra Señora del Rosario de Santo Domingo quedó libre un espacio longitudinal en el lado sur, aledaño al muro lateral del templo. El cabildo había autorizado a los vecinos para que convirtieran este lugar en mercado, pero en 1563 adujo que tenía necesidad de tomarlo «para hacer un templo y otros edificios» y además, porque «es cosa conveniente que se tenga para ornato de esta ciudad». ${ }^{3}$ Con este propósito decretó la expropiación del sitio. La medida fue impugnada por los dominicos, que se opusieron y lo reivindicaron, amparándose en que eran dueños del solar por habérselos adjudicado Francisco Pizarro en 1535 para la construcción de su sede conventual. A fin de establecer el dominio y para determinar los derechos que asistían a los litigantes, fueron convocados peritos que demoraron varios años para emitir el informe resultado de sus pesquisas. Fue así que dos años después, antes de que estuviera el fallo, el cabildo se adelantó y sacó a remate la obra de un templo que se construiría en el lugar y que por entonces se puso bajo la advocación de Santiago. El 10 de julio de 1565 obtuvo la buena pro el maestro de Albañilería Gaspar Báez, con una propuesta tasada en 4300 pesos de plata corriente. De acuerdo a lo que declaró meses después, participó también en el proyecto Alonso Beltrán. La intervención de Beltrán se deduce porque, para poder cumplir con este encargo — que veremos que no era el único que por entonces tenía - tres meses después de ganada la licitación, el 12 de octubre de 1565, Beltrán cedió a Diego de Morales las obras que realizaba para las casas del cabildo. Según lo que declaró en esta oportunidad, la operación respondía a que así podría dedicarse «a la edificación de la fuente e iglesia de Santiago». Cuando decidió traspasarle las obras del cabildo a Morales, Beltrán optó, además, por otra tarea de mayor envergadura en la que también estaba comprometido, que era la obra de la catedral metropolitana, cuyos planos había trazado inspirándose en la de Sevilla. Por otra parte, no podía hacer esperar al cabildo, que había cedido sus solares para que mejorara la orientación de la catedral. Como consecuencia de

Sánchez Concha Barrios, Rafael. «Cofradía de la Vera Cruz. Más de cuatro siglos de historia». El Comercio, suplemento dominical, Lima, 15 de abril, 1990: 9.

Harth Terré, Emilio, «Alonso Beltrán arquitecto y la iglesia de Santiago Apóstol de Lima». Anales del Instituto de Arte Americano e Investigaciones Estéticas, N. ${ }^{\circ} 13$, Buenos Aires, 1951: 73. 
ello, por la urgencia que tenía de contar con un local institucional, había tomado posesión de los solares situados al otro lado de la plaza mayor, que habían sido originalmente destinados para Hernando Pizarro, destacado cofrade de la Vera Cruz, quien desde 1539 se ausentó de Lima para no retornar. ${ }^{4}$

A su vez, Gaspar Báez, el compañero de Beltrán en el contrato de la capilla de Santiago, tenía sus propios problemas. Se había comprometido con los padres de la Compañía de Jesús para venderles unas propiedades en Arequipa, por lo que, presionado por ellos, debía viajar de urgencia a esa ciudad. Así, el 23 de febrero de 1566, Báez traspasó su parte de la licitación de la capilla de Santiago, respetando todas las estipulaciones del convenio, a su compañero de oficio Diego de Morales, ${ }^{5}$ quien ya tenía el encargo de las obras del cabildo que anteriormente le traspasó Beltrán. Sabemos que Morales tenía conocimiento de la participación de Beltrán en la obra, por cuanto lo especificaba claramente en el documento anterior que habían suscrito ambos. Es por ello que reconoció el 21 de marzo de 1566 que, aunque el traspaso a su nombre había sido por la totalidad del encargo, la cuarta parte del derecho sobre el mismo le pertenecía a Alonso Gonzáles Beltrán, de acuerdo a su participación en él. Por el monto que recibió Morales por este concepto, según consigna el contrato, Emilio Harth Terré sugirió que la intervención de Beltrán pudo corresponder a la realización de la traza con la que Gaspar Báez obtuvo la buena pro. Sin negar la posibilidad de que Beltrán diseñara el proyecto, el hecho es que cuando Beltrán cedió la construcción de las casas del Cabildo a Diego Morales el 12 de octubre de 1565, específicamente señaló que lo hacía «por cuanto en mí fueron rematadas las obras de la fuente y de la iglesia del Señor Santiago», a lo que añadió que, además, había obtenido las construcciones para el cabildo de las que en ese momento desistió. Incluso informó que, por entonces, ya estaba trabajando en la obra de la iglesia y que en tres días comenzaría las de la fuente. ${ }^{6}$ Por lo tanto, el porcentaje aludido le habría correspondido en razón de una tarea que por entonces realizaba, antes que exclusivamente por el trazo, que no parece causal suficiente para obligarlo a renunciar a las obras del cabildo. Por otra parte, los tres artífices habían colaborado en otros encargos.

Hernando Pizarro partió a España donde fue confinado en el castillo de La Mota desde 1540 hasta 1565. Murió en 1576.

AGN: Notario Juan Gutiérrez, fol. 139 vta.

AGN: Notario Juan Gutiérrez, fol. 714 vta. 
Beltrán y Báez trabajaron anteriormente juntos en el Hospital de Santa Ana para el arzobispo Jerónimo de Loayza. También existía relación entre Beltrán y Morales, en obras que realizaron para el convento de Santo Domingo y, nuevamente, desde marzo de 1566 volvieron a compartir un proyecto, en este caso la capilla de Santiago. En paralelo, ejercían su oficio independientemente. Alonso Beltrán, a la sazón, estaba encargado de la traza de la tercera y monumental nueva catedral de Lima, de la que fue nombrado Maestro Mayor pero que, finalmente, nunca fue construida. ${ }^{7}$ Por su parte, Morales también estaba por entonces a cargo de la portada de las casas del Arzobispado. Denota esto que los artífices ejercían varios trabajos al mismo tiempo. Es cierto que no abundaban los especialistas por entonces, pero esta fue una práctica permanente durante el virreinato, no solamente referida a obras inmuebles. Pintores y escultores aparecen igualmente recibiendo encargos paralelos. De allí que se justifique que, en algunos contratos, se estipulara que el artista no debería «levantar mano» de la obra encargada o que, si demoraba en exceso en terminarla, la entrega debía pagarla de su propio peculio, sin perjudicar al cliente.

Volviendo a la construcción de la capilla de Santiago y a las circunstancias en las que se estableció, tenemos que la obra se inició en 1565. El concierto con Gaspar Báez señalaba una iglesia «al Señor Santiago que se ha de hacer en la plazuela de María Escobar», que es como en algunos documentos aparece señalada la zona situada frente a la puerta lateral de la iglesia dominica y la denominación por la que la reconoce el cabildo. Como hemos mencionado, a pesar de la apelación interpuesta por los dominicos y al nombramiento de peritos, que aún no habían entregado informe alguno, la construcción no se detuvo. Desde que se entabló la demanda, el trámite demoró casi hasta que finalizaron las obras en 1570.

Entonces se produjo una modificación importante. Una vez que se hubo terminado la construcción de la capilla, la advocación a Santiago fue cambiada por la de La Vera Cruz. La nueva denominación se sustentó en razones religiosas, tanto como políticas y administrativas, vinculadas a la exclusiva cofradía que existía en la iglesia dominica, a la que también se conocía como de los caballeros.

Harth Terré, op.cit., p. 64. 
De acuerdo a sus estatutos, el cabildo era el Patrón de la Hermandad de la Vera Cruz, por lo que estuvo entre sus atribuciones la decisión que dio por finalizado el conflicto con la Orden dominica. En la iglesia originalmente de Santiago, se acordó que fuera albergada la reliquia más importante con la que contaba el virreinato, a la que posteriormente se agregaron otras de similar calidad. No podía oponerse la Orden dominica a esta propuesta. Así, se trasladó la cofradía de la Vera Cruz al nuevo local, con lo que el cabildo culminó el proyecto, los dominicos obtuvieron una extensión para su sede institucional, quedando saldada la controversia y se beneficiaron los cofrades. El relicario de Sanctum Lignum Crucis fue debidamente colocado en el altar mayor de la Vera Cruz, de donde se dice que desapareció durante la guerra con Chile, por lo que para reponerlo fue enviado otro fragmento, aunque de menor tamaño. Lo que sucedió con la advocación de Santiago fue que la destinaron a la iglesia en la Reducción de Indios de Santiago en el Cercado, cuando fue creada la locación y terminada de construir por la Compañía de Jesús. Sin embargo, no fue totalmente olvidado el culto al apóstol porque en la capilla de Diego de Agüero en Santo Domingo, colindante a la de Vera Cruz, se celebraba «misa mayor el día de Santiago, en el cual día tiene un jubileo plenísimo», recordaba Reginaldo de Lizárraga a inicios del siglo XVII. ${ }^{8}$

En lo que concierne al aspecto general del templo, la disposición del terreno no dio lugar a mayores complicaciones. El investigador, Dr. Antonio San Cristóbal Sebastián, ${ }^{9}$ señala que este primer edificio tuvo planta longitudinal góticoisabelina, esto es de una sola nave y capillas hornacinas poco profundas en los laterales, a lo que se agregó un coro en una tribuna sobre la puerta de ingreso. Parte de la apariencia externa que tuvo este edificio podemos deducirla de un hecho paralelo relacionado a otra construcción, el que le añade un significado adicional. El 15 de febrero de 1570 se celebró un contrato entre el licenciado Luzio, como prior de la cárcel del cabildo y Pedro Vergara, mayordomo de la Capilla del Cabildo, con Alonso de Morales para la ejecución de las portadas de la capilla. Alonso de Morales era hijo de Diego de Morales, vinculado a la

Lizárraga, fray Reginaldo. Descripción breve de toda la tierra del Perú, Tucumán, Río de la Plata y Chile (1603-1609). Madrid, Biblioteca de Autores Españoles. 1968, Cap. XXIII.

$9 \quad$ San Cristóbal Sebastián, Antonio, Fray Diego Maroto alarife de Lima. 1617-1696. Lima, Editores Epígrafe, S.A., 1996, 137-142 ss. 
Capilla de la Vera Cruz, lo que probablemente, fue un hecho que se consideró cuando se le convocó. El contrato estipulaba que debía hacer «dos portadas de ladrillo, la una en la calle de Don Antonio y la otra que sale a la plaza donde solían ser poco más o menos desviadas, labradas de la forma que está la puerta de la Capilla de la Veracruz, con sus serafines de barro cocido y otras figuras»». ${ }^{10}$ Esta aplicación ornamental, de origen italiano, se empleó en Lima hasta fines del siglo siguiente, ${ }^{11}$ añadiendo un rasgo de color a las con frecuencia sobrias construcciones españolas. Un antecedente próximo de esta aplicación se encuentra en España. El italiano Francesco Nicoloso de Pisa, llegó a Sevilla hacia 1500 e imprimió un gran impulso a la técnica cerámica, en la que también introdujo temas renacentistas y mayor riqueza en el color, ${ }^{12}$ que aplicó a retablos motivos decorativos y azulejería, con proyección en toda la península, en especial en Talavera de la Reina, donde por un tiempo estableció su taller. En compañía de Pedro Millán, había inaugurado esta técnica en España en 1503, en la portada de la iglesia de Santa Paula en Sevilla, las que se decoraron «con relieves de barro esmaltado». ${ }^{13}$ Existía, pues, una tradición que tuvo éxito en las primeras construcciones limeñas. Pudo concentrarse en Alonso de Morales el ejercicio que supuso el encargo, o tratarse de un trabajo en colaboración. Por estudios recientes conocemos que la técnica cerámica cobró progresivamente mayor importancia en la ciudad, en la que se establecieron maestros calificados que permitieron la formación de talleres especializados. ${ }^{14}$ Respecto al contrato, encontramos que también era frecuente en la época virreinal, en todo tipo de convenios, que se tomara un modelo previo de efecto comprobado, para repetirlo, intención que se refuerza cuando se decide contratar al hijo de uno de los responsables del modelo. No desmerece esto en absoluto la calidad del artífice ni supone un demérito personal. Simplemente, así como los artistas plásticos recurrieron a modelos previamente realizados por maestros mayores, que se

10 AGN ante Juan García Tomino. 1569 -1570; Ramírez LEÓn, Luis. Juan del Corral y la azulejería limeña del siglo XVII. Tesis de Licenciatura en Arte. Lima, Universidad Nacional Mayor de San Marcos, EAP. de Arte, 2002. Inédita, cita 54; Harth- Terré, Alonso. cit., consigna la fecha 17 de febrero.

11 San Cristóbal, Antonio. Fray Cristóbal Caballero y la portada de la Merced de LimaAnuario de Estudios Americanos, 1991, para la Encarnación, en: RAmíreZ, op. cit., p. 35.

12 Selva, José, El arte español en tiempo de los reyes católicos. Barcelona, editorial Amaltea, S.A., Speculum Artis, 1943, $204-205$.

13 Selva, op.cit., p. 92. Ramírez, op.cit., p. 35, añade que se trató de tondos y medallones.

14 RAmírez, op.cit. passim. 
difundieron por medio de grabados, para inspirarse en sus propias composiciones, cuando no copiarlas minuciosamente por expreso encargo de los comitentes, de la misma manera, el cliente que encargaba una construcción elegía aquello que deseaba reproducir en sus dominios y el artífice debía estar en condición de satisfacer su demanda.

El mismo año en el que, ratificando su importancia, la Vera Cruz fue elevada al rango de Archicofradía, un nuevo hecho destacó su existencia en la Lima virreinal, el que pudo ser favorecido por sus pequeñas proporciones y la estrechez de su planta longitudinal. El 7 de julio de 1586, a las 7 de la noche, la ciudad sufrió un fuerte movimiento telúrico que dañó seriamente las iglesias de Santo Domingo, San Francisco, San Agustín, La Merced, la mayor parte de la Catedral y muchos locales públicos y viviendas. El único edificio que no sufrió percances de consideración fue el de la Vera Cruz. Como la sede del cabildo había quedado inhabitable, el virrey Conde del Villar, después del reconocimiento de los daños, ordenó que las sesiones de la audiencia se llevasen a cabo en la pequeña capilla. Pero casi un mes después, el 12 de agosto, el virrey convocó a los oidores para informarles que, debido a los temblores que siguieron al terremoto y especialmente, a uno de consideración del 10 de agosto «se ha dificultado si están seguros los dichos señores en el tiempo que hiciesen audiencia y estuvieran en la dicha capilla y las demás personas que concurren a los negocios». Posiblemente porque los daños no eran evidentes, en tanto no eran de consideración, los oidores decidieron continuar las sesiones a falta de un lugar más apropiado. Sin embargo, se tomó la precaución de convocar a peritos que determinaran «si está sin peligro para hacer las dichas audiencias». ${ }^{15}$

En 1613, la iglesia sufrió una reforma: el cambio de la portada con motivos de cerámica, que estuvo vigente poco más de cuarenta años. Los términos del convenio se ajustaron al uso del modelo como referencia, similar al señalado anteriormente. Los mayordomos de la Archicofradía, Juan Fernández Ramírez y Francisco de Sosa, firmaron un contrato con el maestro de albañilería y arquitectura Diego Guillén, para que construyese una nueva portada. Se estipuló que «en la puerta de la capilla de la dicha Santa Veracruz hará de nuevo una portada

15 Lisson Chávez, Emilio, La Iglesia de España en el Perú. Colección de documentos para la historia de la Iglesia en el Perú, Sevilla, 1943, vol. III, N. ${ }^{\circ} 4$. 
de ladrillo como la de la capilla de Nuestra Señora de la Soledad, demás que ha de tener dos columnas amelonadas sobre sus pedestales de más de una vara de alto con la obra conveniente a la dicha portada, y se obligó que a su costa derribará la portada que de presente está hecha... para hacer de nuevo, todo ello por cuatrocientos pesos de a ocho (reales) ayudando a sentar las puertas en lo que fuera de su oficio y dejarlo todo enlucido y revocado». ${ }^{16}$

Casi 30 años después, la cofradía planteó al cabildo un reclamo que condujo a una nueva intervención en el edificio, respecto al pedido que se planteó a favor de que fuera ampliado el terreno sobre el que se había construido la primera capilla, basándose en que no concordaba con el perímetro del convento. Se incluyó como alegato la necesidad de levantar una nueva construcción «con decencia y capacidad como es justo la tenga un sagrario tan ilustre». ${ }^{17}$ El cabildo, en su sesión del 10 de octubre de 1646, previo informe de peritos, resolvió favorablemente.

El padre Antonio San Cristóbal ha encontrado documentación por la cual esta nueva propuesta arquitectónica se llevó a cabo probablemente en 1646. Correspondería por tanto a la que aparece en el plano de la crónica de Juan Meléndez. Esta nueva capilla de la Santa Veracruz se levantó en el mismo emplazamiento de la primera del siglo XVI, con la atingencia que amplió su ancho en una vara hacia el lado sur, de acuerdo a lo solicitado al cabildo. El edificio estuvo a cargo del alarife Domingo Alonso, según una carta de pago por este concepto, del 12 de marzo de 1650 que ha localizado San Cristóbal. El contrato no ha sido encontrado, pero este autor propone que Diego Maroto habría estado a cargo de la traza y de las condiciones de la fábrica, porque coinciden con el estilo del maestro y porque además, en la capilla se inauguró en Lima una solución tipológica que le pertenece.

De acuerdo al grabado del conjunto dominico de fray Rodrigo Meléndez (1681 82), ${ }^{18}$ la disposición espacial de la capilla de la Vera Cruz es sencilla. De una sola

16 AGN: Notario Francisco Hernández. 16 de mayo de 1613. fol. 1026. Testigos: Francisco Hernández Vásquez, Juan Narváez y Alonso Ramírez.

17 San Cristóbal. Diego Maroto, cit., p. 139.

18 MelÉndez. O.P., Rodrigo, Tesoros verdaderos de Indias en la historia de la gran Provincia de San Juan Bautista del Perú, de la Orden de Predicadores, 1681, Roma, Imprenta de Nicolás Ángel Tinassio, MDCXXXI. 
nave cuatro tramos, crucero con cúpula y capilla absidial profunda. El texto que acompaña el grabado informa que en el cuarto tramo, en el lado del evangelio, se encontraba el retablo del Ecce Homo. Frente a él, en el lado de la epístola, se abría la puerta que, mediante un pequeño corredor transversal, permitía la conexión con la iglesia mayor, a los pies de la capilla de los Agüero, actualmente de Nuestra Señora del Rosario. En el grabado se observa un pasaje, a manera de corredor longitudinal, en el que las puertas que comunicaban la capilla con la iglesia quedan situadas al nivel de la mitad. Este sector establece un espacio de separación entre ambas dependencias y, a su vez, aparece dividido en dos ambientes a cada lado, comunicados entre sí en dirección longitudinal. En la habitación del extremo Este de esta sección, otra puerta se abre directamente al costado izquierdo del retablo de la capilla de Santa Ana, a la altura del quinto tramo de la iglesia del Rosario. Toda la zona es identificada por Meléndez como la sacristía. De acuerdo al mismo plano, detrás de la capilla de Juan de Aliaga y comunicada con ella por las dos pequeñas puertas que flanquean el retablo, aparece una habitación, igualmente señalada como Capilla de la Vera Cruz, que pudo ser el emplazamiento de la primitiva fundación pizarrista. Tiene conexión directa con la capilla mayor a través de un pequeño corredor.

El templo se adornó con profusión de retablos, destacando el del altar mayor que resguardaba el relicario del Sanctum Lignum Crucis. En la nave, colocados en capillas del tipo hornacina poco profundas, más cercanas al tipo arcosolio, destacaban en la zona del crucero los retablos de la Pasión de Cristo en el lado del Evangelio y de Nuestra Señora de las Angustias en el lado de la Epístola, iluminados por la cúpula. Frente al púlpito y a la puerta del corredor de acceso a la sacristía, estaba el retablo del Ecce Homo ya mencionado.

De acuerdo al grabado de Rodrigo Meléndez, en el que se registra el exterior del conjunto dominico, observamos que la portada de la capilla era una obra de dos cuerpos. El primero termina en un entablamento corrido, con un frontón abierto que destaca sobre un ático, más angosto que la base sobre la que se asienta. Esta sección parece estar limitada por dos pilastras de corte cuadrangular y termina en un friso ligeramente resaltado. Dos columnas lisas sobre una pequeña base flanquean la portada. Alrededor de ésta se practicaron dos finas molduras. El segundo cuerpo, menor en dimensión que el anterior, se apoya en el ático. Presentaba una hornacina central con pilastras y dos volutas a manera 
de aletas a los lados, como un recurso para vincularlo con la sección inferior. Este cuerpo remata en un frontón semicircular cerrado, en el que figura una cruz en la zona de la clave. A los lados de la portada hay dos ventanas cuadrangulares. El límite superior del muro es de altura inferior al de la iglesia mayor, por lo que se aplicó una cartela en el vértice de encuentro. Para el padre Juan Meléndez, la capilla era «de por sí una muy capaz iglesia» y su detalle más destacado era la cúpula, la que consideró como «una gran maravilla, por sus cuatro ventanas entre relieves, linterna y pechina», ${ }^{19}$ ventanas que no forman parte de esta cubierta actualmente.

En 1653 pudo estar concluido este edificio, de acuerdo a un documento en el que se advierte, además, otra mecánica frecuente en la arquitectura virreinal: la costumbre de transformar o reutilizar elementos de un edificio en otro, a veces variando su función. En 1653, Tomás Suárez Gilis compró al maestro Diego de Mondragón las puertas que habían sido de la antigua Capilla de la Vera Cruz, que éste había obtenido como parte de pago por hacer las nuevas en madera. Estas puertas fueron posteriormente colocadas en una casa particular. ${ }^{20} \mathrm{El}$ procedimiento fue frecuente en el virreinato para todo tipo de elementos arquitectónicos, tanto estructurales como ornamentales.

Pocos años después, el terremoto del 20 de octubre de 1687 tuvo un efecto devastador en Lima. Esta vez el edificio de la Vera Cruz quedó dañado seriamente, como informa el cabildo en abril del año siguiente. En el documento el artífice Fernández Montaño, luego de señalar la total destrucción de los edificios de la ciudad, añadió que «de la misma suerte quedó la iglesia de la Veracruz, pues no quedó en toda ella cosa alguna, porque se arruinó»». ${ }^{21}$ Fue por eso que los padres de la Orden de Santo Domingo, al no poder utilizarla y porque en la iglesia no había lugar aparente adonde pudiesen acudir los fieles, aparte de la capilla de Nuestra Señora del Rosario, se vieron precisados a habilitar una en la plaza mayor.

19 MelÉndeZ, op.cit., I, p. 58.

20 Harth Terré, Emilio, «La casa urbana virreinal, Lima», Revista del Archivo Nacional del Perú, tomo XXVI, E. I, enero-junio, 1962, 200.

21 Angulo, O P. Diego. «El terremoto de 1687, Información que fizo por el Cabildo, Justicia y Regimiento desta y Theniente del cabildo, de la ruina que padeció esta ciudad con el terremoto...», Lima, Revista del Archivo Nacional del Perú, t. XII, E. I, enerojunio, 1939, 30. 
A pesar de la magnitud del otro terremoto del 28 de octubre de 1746, ninguna noticia adicional se ha podido localizar hasta el año 1780, en que se tomó la decisión de reemplazar el retablo que ponderó Meléndez en su crónica. El escultor José Pérez Mendoza se comprometió a hacer el retablo principal de la capilla de acuerdo al gusto imperante, por lo que señala que lo hará de «estilo moderno». ${ }^{22}$ Respecto a la estructura interna del templo, basándonos en el documento gráfico de Meléndez y a su apariencia actual, poco se ha modificado en la Vera Cruz, incluso de haber sufrido tan seriamente como se consigna en 1687 y probablemente en 1746, que no fue poca la magnitud del sismo. En 1812 Matías Maestro, en colaboración con José María Perrin, realizó los trabajos conducentes a rehabilitar la capilla. ${ }^{23}$ Es posible que incluyera en ello a la portada.

Después del terremoto de 1940, cuando se reparó la iglesia de Santo Domingo, se hicieron también arreglos en la Vera Cruz. Los trabajos estuvieron bajo la supervisión del arquitecto Emilio Harth Terré, basados en trazados suyos y de E. W. Moser. En esta oportunidad se trató de devolver a la fachada el estilo que tenía en el siglo XVII, de acuerdo al grabado de 1681 publicado en la obra de Juan Meléndez, el que sirvió de guía a los restauradores. Un detalle a señalar es que la fachada que aparece en el grabado de Meléndez, descrita anteriormente, presenta menos similitud con la fachada supuestamente recuperada que aquella que aparece en fotografías anteriores a 1900. En los primeros años del siglo XIX la fachada aún era la que debió diseñar Maestro, pero todo el templo fue nuevamente intervenido entre 1903 y 1906 y parcialmente, en años sucesivos.

La construcción de esta pequeña capilla es un ejemplo de la dinámica contractual y de ejecución que conducía estas empresas, la que comprometía la intervención de las autoridades virreinales, de las órdenes religiosas y de los artífices convocados para cumplir los encargos. Cada estamento se condujo de acuerdo a sus propios intereses y emprendió las medidas necesarias para beneficiarse con los resultados. Ejercieron su dominio en el ámbito que les correspondió, desarrollando tareas que, en conjunto, concretaron proyectos monu-

22 Vargas Ugarte, S. J. Rubén. Ensayo de un diccionario de artifices de América Meridional, Burgos, Imprenta de Aldecoa, segunda edición, 1968, 442.

23 Harth Terré, Emilio y Alberto Márquez Abanto, «Las Bellas Artes en el Virreinato. Pinturas y Pintores en Lima virreinal», Lima, Revista del Archivo Nacional del Perú, t. XXVII, E. I y II, 1963, 205. 
mentales. Éstos, a su vez, constituyen documentos de procesos histórico sociales a través de los cuales podemos acercarnos a su mejor comprensión como objetos de la historia del arte peruano.

\section{ApÉNDICE DOCUMENTAL}

\section{1.- Cesion Alonso Gonzales Beltrán a Diego Morales}

12 de octubre de 1565. Notario Juan Gutiérrez. Fol. 714 vta.

.. . en la fecha Alonso Gonzáles Beltrán albañil morador de esta ciudad de los Reyes ... otorgo que por cuanto en mí fueron rematadas las obras de la fuente y de la iglesia del Señor Santiago y de las casas del Cabildo y atento a que yo estoy haciendo la obra de la dicha iglesia y tener que empezar la obra de la dicha fuente de hoy en tres días y asimismo había de empezar luego la obra del dicho Cabildo y dallas fecha dentro de cierto tiempo conforme a las condiciones y atento a que no la podré proseguir mediante lo cual otorgo e conozco que cedo e traspaso la obra de las casas del dicho Cabildo en vos

Diego de Morales albañil . . p para que empecéis y hagais y acabeis según y conforme a las condiciones con que a mi me fue rematada e cobreis a la Justicia desta dicha ciudad los trescientos noventa pesos en que a mi me fue rematada. . . Y yo el dicho Diego de Morales que a lo que dicho es soy presente otorgo que la acepto en mí y me obligo de hacer la dicha obra según y conforme a las dichas condiciones y de la manera que vos el dicho Alonso Gonzáles Beltrán estais obligado y no la haciendo en el término que vos estais obligado pagaré las penas . . Testigos: CRISTÓBAL DE SORIA Y PEDRO DE PRADO Y PEDRO ARJONA.

Archivo particular Emilio Harth-Terre. S. XVI (1980). 


\section{2.- Traspaso. Gaspar Báez a Diego De Morales}

23 de febrero de 1566. Notario Juan Gutiérrez. Fol. 139 vta.

... en la fecha Gaspar Vaez albañil morador en esta ciudad de los Reyes ... otorgo que por cuanto en mí fue remata la obra de la iglesia del Señor Santiago que se ha de hacer en la plazuela de María de Escobar en cuatro mil trescientos pesos en plata corriente con ciertas condiciones como se contiene en el remate en mi fecho en esta ciudad en diez de julio de mil quinientos sesenta y cinco a que me refiero y porque yo estoy ocupado y no puedo hacer la dicha obra por tanto otorgo y conozco que hago cesión y traspaso della y con las dichas condiciones y según y en la dicha manera que en mí fue rematada en vos Diego de Morales albañil residente en esta dicha ciudad para que hagais la dicha obra y la prosigais y por ella ayais y cobreis los dichos cuatro mil trescientos pesos . . Yo Gaspar de Ledesma salgo por fiador del dicho Diego de Morales.

Testigos. PEDRO DE PRADO Y GONZALO BOLANTE Y AMBROSIO DE MOSCOSO.

Archivo particular Emilio Harth-Terre. S. XVI (1980).

\section{3.- Declaración: Diego de Morales.}

21 de marzo de 1566. Notario: Juan Gutiérrez. Fol. 173 vta.

... en la fecha Diego de Morales albañil morador de esta ciudad de los Reyes . . . otorgo que por cuanto en Gaspar Vaez fue rematada la obra de la iglesia del Señor Santiago que se ha de hacerse en la plazuela de María de Escobar en cuatro mil trescientos pesos en plata corriente con ciertas condiciones como se señala en el remate en el hecho en esta ciudad en diez de julio de mil quinientos sesenta y cinco la cual dicha obra el dicho Gaspar Vaez me traspasó ante el presente escribano . . . por tanto otorgo y conozco y declaro que no embargante que toda la dicha obra se traspasó en mi es y pertenece la cuarta parte a Alonso Gonzáles Beltrán y confieso que para en cuenta he recibido setecientos sesenta y nueve pesos de los cuales soy e me otorgo por bien contento ... Testigos: PEDRO DEL PRADOGONZALO BOLANTE -PEDRO GUTIERREZ MESA.

Archivo particular Emilio Harth-Terre. S. XVI (1980). 


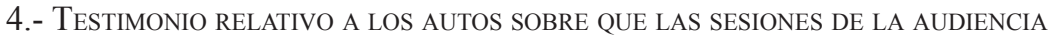 DE LOS REYES SE CELEBREN EN LA CAPILla DE LA VERACRUZ A CAUSA DEL TERREMOTO DE ESTE AÑO.}

\section{AGOSTO, 1958}

A. de Lima, 108

En la ciudad de los Reyes doce días del mes de agosto de mil quinientos ochenta e seys años el Excelentísimo Señor don Francisco de Torres y Portugal Conde del Villar Virrey y Gobernador y Capitán General por su Majestad destos Reynos y provincias del Perú presidente de la Real Audiencia que reside en esta ciudad y de las demás destos Reynos mando a Diego Martínez portero desta dicha Real Audiencia que avisase y llamase a los señores de la Real Audiencia y Alcalde de Corte y fiscal de la dicha Real Audiencia y Oficiales Reales, el cual aviendo avisado y llamados y ellos venidos a acuerdo e juntos en el con Su Excelencia, Su Excelencia dijo que después del acuerdo último parece que las paredes de la Capilla de los Cofrades de la Veracruz donde se hazia la Audiencia de los señores Presidentes y oidores se maltrato con ellos principalmente con uno que fue a diez deste presente mes en la noche que se ha dificultado si estan seguros los dichos señores en el tiempo que hizieren audiencia y estuvieren en la dicha capilla y las demas personas que concurren a los negocios, sobre lo qual habiéndose conferido en este acuerdo hallándose Su Excelencia presente con los dichos señores oidores y alcaldes y fiscal y Oficiales, el señor Doctor Artiaga fue de parecer por la disposición que tiene la dicha capilla, que en ella se continúe el hazer las audiencias hasta que se reduzga a su lugar, y los lemas señores fueron de parecer que lo vean alarifes para que si esta sin peligro para hazer las dichas audiencias y $\mathrm{Su}$ Excelencia mandó que los señores Oficiales Reales llamen a los larifes desta dicha ciudad y demas oficiales que parezcan que convengan para que vean la dicha capilla y con juramento declaren si está sin peligro para en ella poderse hazer las dichas audiencias la qual declaración se traiga al primer acuerdo para que sobre ello se trate y confiera y determine lo que mas pereciere que convenga.

EL CONDE DEL VILLAR, EL Ldo. RAMÍREZ DE CARTAGENA, EL DR. ARTEAGA, EL DR. ALONSO CRIADO DE CASTILLA, EL LDO. FRANCISCO DE CARDENAS, EL LDO. DN DIEGO LOPEZ DE ZÚÑIGA, EL DR. CARVAJAL, DN FRANCISCO MANRIQUE DE LARA, ANTONIO DE AVALOS, TRISTAN SÁNCHEZ, Ante mí JUAN VELLO. Concuerda Con el original.- JUAN VELLO (rubricado).

Mons. Emilio Lisson Cháves, op.cit., Siglo XVI, vol. III, N. ${ }^{\circ} 14$ (Documentos desde 1583 a 1585), 423-424. 
5.- RELACION DE LAS CIUDADES, VILLAS Y LUGARES PARROCHIAS Y DOCTRINAS QUE HAY EN ESTE ARZOBISPADO DE LIMA, DE ESPAÑOLES

Y DE INDIOS: Y DE LAS PERSONAS QUE LAS SIRVEN, ASSI CLERIGOS COMO RELIGIOSOS, DEL NÚMERO DE FELIGRESES QUE CONTIENEN Y DE LAS COFRADIAS Y HOSPITALES QUE AY EN LOS DICHOS LUGARES, SUS RENTAS Y ADCOCACIONES (FRAGMENTO)

Año 1619, 19 de Abril

A. De Lima 301

(. . .) Cofradías de Lima, relación de las Cofradías que ay en Lima en la Santa Iglesia Cathedral y en las Parrochias y conventos assi de frayles como de monjas y la renta que cada una de ellas tiene cada año situada y la que piden limosna assi las que son españoles indios negros y mulattos y en que se distribuye la dicha renta que todo es en la forma siguiente.

La Cofradía de la Vera-cruz fundada en la dicha iglesia tiene de renta en censos noventa y un petacones y siete reales y junta de limosna cada año dos mil pesos poco mas o menos que los unos y los otros se gastan en servicio de la dicha cofradia y en la procession de sangre que haze el juebes Santo y en otras cosas tocantes al servicio de la dicha cofradía.

Mons. Emilio Lisson Cháves, op. cit., S. XVII.

\section{6.- Concierto Diego Guillén con los MAyordomos DE LA SANTA VERACRUZ.}

Notario: Francisco Hernández.

16 de mayo de 1613 (Fol. 1026)

... en la fecha Diego Guillén maestro albañil morador de esta ciudad de los Reyes ... dijo que era convenido y concertado con Juan Fernández Ramírez y Francisco de Sosa mayordomo que al presente son de la cofradía de la Santa Veracruz fundada en el convento del Señor Santo Domingo de esta ciudad en tal manera . . . que se obligaba y obligó que en la puerta de la capilla de la dicha santa Vera-cruz hará de nuevo una portada de ladrillo como la portada de la capilla de Nuestra Señora de la Soledad demas de que ha de tener las columnas amelonadas sobre sus pedestales de mas de una vara de alto con la obra conveniente a la dicha portada y para hacer la dicha obra se obligó que pondrá peones y oficiales de forma que 
los dichos mayordomos tan solamente le han de dar los materiales que fueren menester para hacer la dicha obra ... y asimismo se obligó que a su costa derribará la portada que de presente está hecha en la dicha capilla para poder hacer la otra de nuevo ... toda la cual y enlucida y cinteada de blanco la pared de la dicha capilla y acabada de todo punto a vista de oficiales lo haré hecho y acabado para fin del mes de agosto que vendrá de este año ... y por la ocupación y trabajo que en esto he de tener los dichos mayordomos me han de dar cuatrocientos pesos de a ocho reales ... doscientos que he recibido de contado ... y si no la diere acabada para dicho plazo le han de pagar tan solamente trecientos pesos ... y en esta manera se obligó de hacerla y cuando sea asienten las puertas de la dicha capilla ayudará asentarlas en lo que fuere de su oficio y dejarlo todo enlucido y rebocado.Testigos: Francisco Hernández Vásquez -Juan Narvaez -Alonso Ramírez.

Archivo particular Emilio Harth-Terré. S. XVI (1980). 